\title{
تقدير الإحتياجات الإرشادية لزراع الرمان ببعض قرى محافظة أسيوط
}

\author{
محمد محمد محمد عبد الغني \\ قسم المجتمع الريفي والإششاد الزراعي، كلية الزراعة، جامعة أسيوطا
}

Received: Jan. 15, 2020

Accepted: Jan. 29, 2020

الملخص:

إستهذف البحث بصورة رئيسية تقدير الإحتياجات الإرشادية لزراع الرمان ببعض قرى محافظة أسيوط، وبثكل أكثر

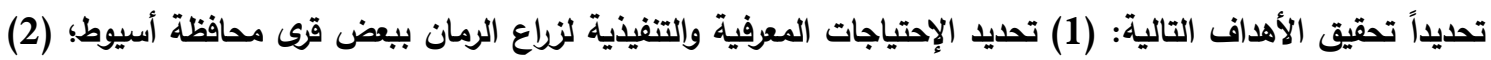

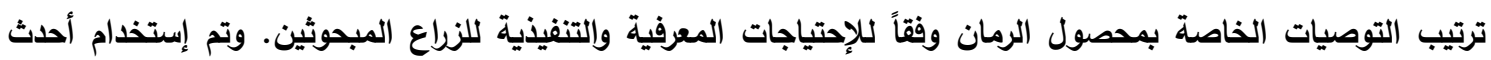
طرق تقدير الإحتياجات التي أمكن الإطلاع عليها (معادلة Delta N المعدلة، وإلمدخل الجديد لتقدير الإحتياجات)، وأجريت الاراسة على عينة عشوائية بلغت 234 مبحوثاً من زراع الرمان بقريتين بمحافظة أسيوط. وتم جمع البيانات باستخدام

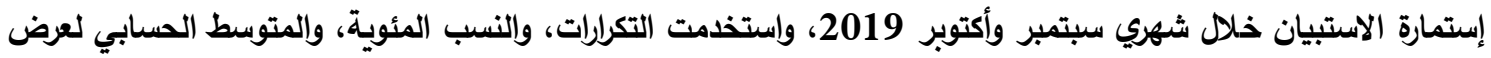

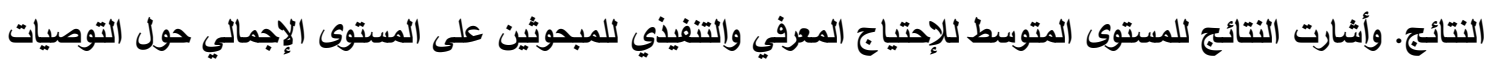

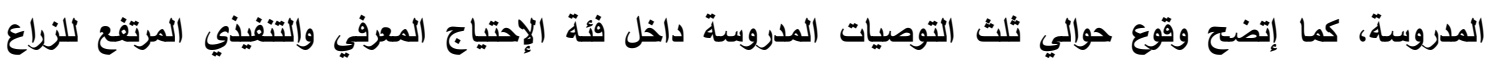

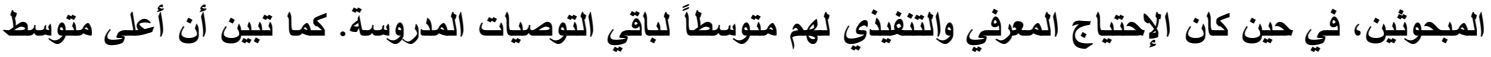

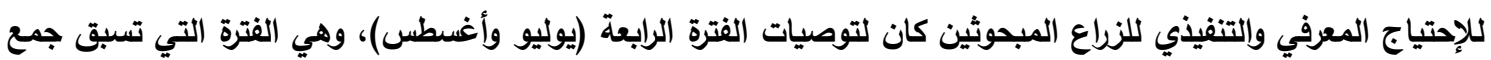

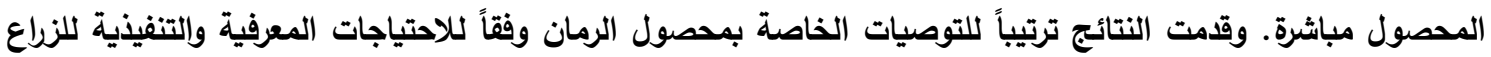

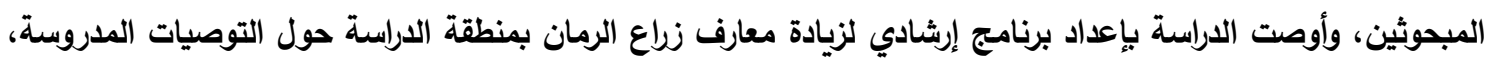

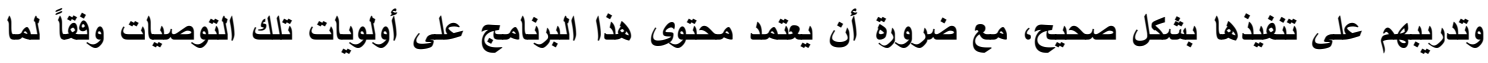
أشارت إليه نتائج الاراسة الحالية حول ترتيب تلك التوصيات وفقاً للاحتياجات المعرفية والتنفيذية للزراع المبحوثين. الكلمات الدالة: الإحتياجات الإرشادية، معادلة Delta N المعلة، المدخل الجديد لتقدير الإحتياجات، محافظة أسيوط .

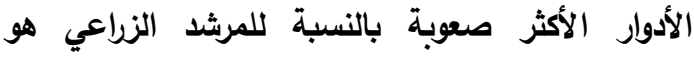
التعرف على تلك الإحتياجات، وذلك لارتباط نجاح المرشد الزراعي بثكل كبير بلرجة توافق دوره مع احتياجات

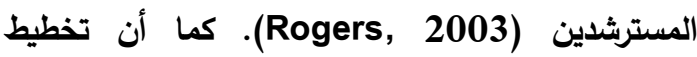

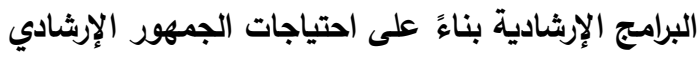
يضمن توفير الوقت والجها والتكاليف للعاملين بالإرشاد من ناحية، وزيادة رغبة ودوافع المزارعين في المشاركة

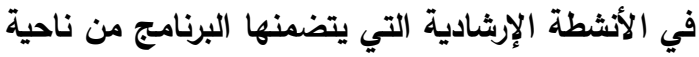

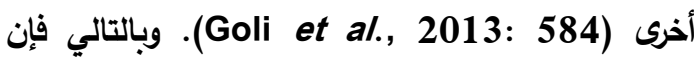
نجاح البرامج الإششادية يعتمد على تحديد الإحتياجات
المقدمة والمشكلة البحثية يمتلك المزارعون مجموعة من المهارات الفطرية والمتعلمة التي تؤثر على الطريقة التي يؤدون بها ممارساتهم الزراعية، ويمكن أن توفر خدمات التمات الإرشاد المعرفة وإلمهارات اللازمة لتحسين كيفية أداء المزارعين لتلك الممارسات من خلا البرامج الإرشادية المناسبة (Goodwin and Gouldthorpe, 2013: 55) ويعد تقدير الإحتياجات نقطة البداية والدعامة الأساسية

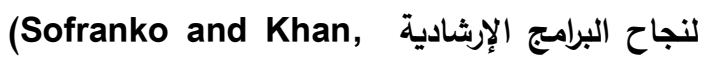
(1988، حيث تعتمد فعالية البرامج الإرشادية على الارئادية استنادها لحاجات المسترشدين، وبالتالي فإن أحد أهم 
من حيث الأهمية النسبية للمحافظات المنتجة لمحصول الرمان، فقد بلغ إنتاج المحافظة عام 2016 ما يعادل \% 40,1 من جملة إنتاج الجمهورية (وزارة الزراعة

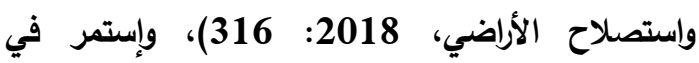

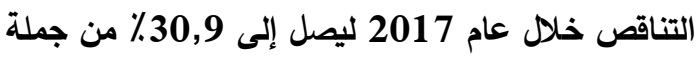
إنتاج الجمهورية (وزارة الزراعة واستصلاح الأراضي،

.2019

وفي ضوء ما سبق، فإنه يجب توجيه الجهود

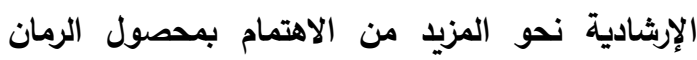

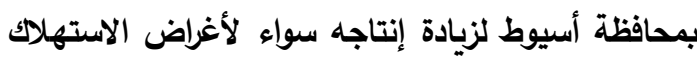

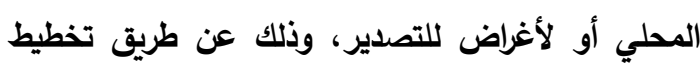

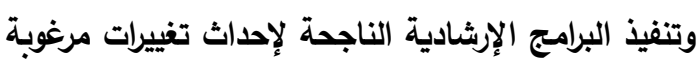

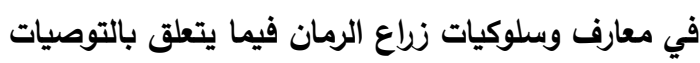

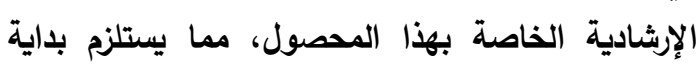
تقدير الإحتياجات الإرشادية المعرفية والتنفيذية لزراع الرمان بمحافظة أسيوط. أهداف البحث:

يستهاف البحث الحالي بصورة أساسية تقدير

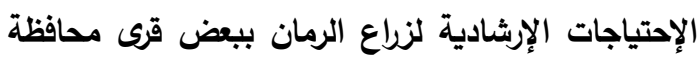

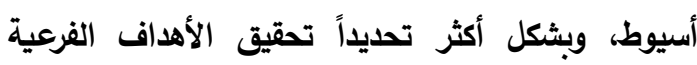
التالية:

1- تحليد الإحتياجات المعرفية والتنفيذية لزراع الرمان

$$
\text { ببعض قرى محافظة أسيوط. }
$$

2- ترتيب التوصيات الخاصة بمحصول الرمان وفقاً

للاحتياجات المعرفية والتنفيذية للزراع المبحوثين.

$$
\text { 1 الإطار النظري }
$$

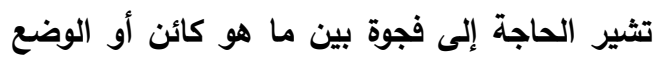

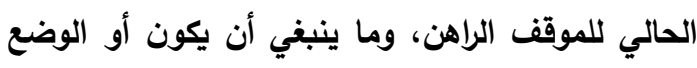
المرغوب (6ltschuld and Watkins, 2014: ويعبر تقدير الإحتياجات عن عملية تحديد الإحتياجات

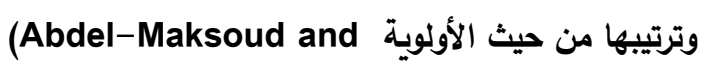

(Abdel-Maksoud, بدقة وترتيبها من حيث الأولوية .2010: 205)

ويعتبر الرمان من محاصيل الفاكهة ذات الأهمية

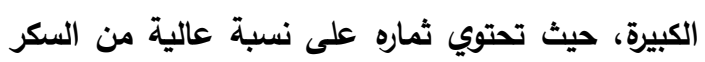

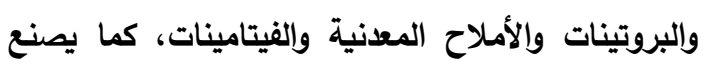
من عصيره دبس الرمان الذي يضاف للطعام ويستخدم

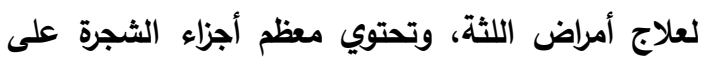
مادة التانين التي تستخدم في دباغة الجلود، وتحتوي

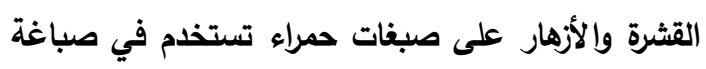
الحرير وتلوين الحلوى وصناعة مستحضرات التجميل، كما تستخدم الأولق في صناعة الحبر. ويتميز الرمان

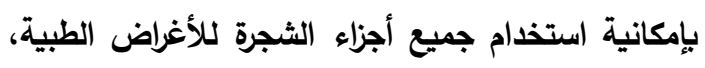
حيث يساعد العصير في علاج بعض أمراض القلب إنباء والكلى وارتفاع ضغط الام، ويستخدم مطحون قشر الرمان

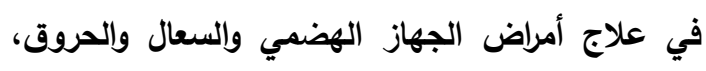

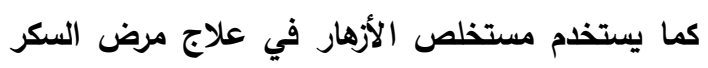
والأنيميا، إلى جانب استخدام زيت بذور الرمان في علاج سرطان الثاي والرئة (الادارة العامة للثقافة الزراعية، 2015 وتعتبر مصر من أكبر دول العالم إنتاجاً للرمان، حيث تحتل المركز السابع على مستوى العالم من حيث الكمية المنتجة من الرمان، كما تعتبر ثالث دول العالم المصدرة للرمان، حيث بلغت كمية صادرات مصر من الرمان

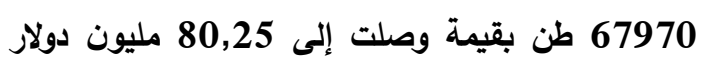

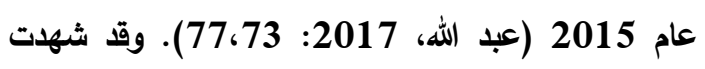
السنوات الأخيرة زيادة ملحوظة في انتاج الرمان في مصر، حيث ارتفع الإنتاج المحلي من 2005 2005 إلى 3817 2017 381426 طن عام 2017 (عبد الله، 2017: 38؛ 2019: 2017: 325). وتصدرت محافظة أسيوط ترتيب محافظات الجمهورية في إنتاج الرمان على مدار الفترة

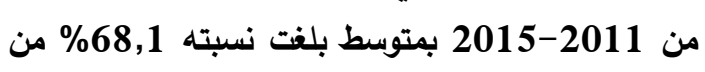
جملة إنتاج الجمهورية (عبد الله، 2017: 36 36)، ولكنها تراجعت للمركز الثاني بعد النوبارية خلال الأعوام التالية 
تصميم وتنفيذ البرامج الإرشادية التي تستند إلى أهداف

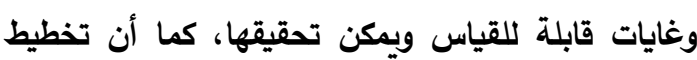
البرامج الإرشادية بناءً على احتياجات المسترشدين يزيل من إحتمال نجاح تلك البرامج، وذلك عن طريق تحسين إمكانية وصول الخدمات الإششادية إلى المسترشدين، وتوفير معلومات كافية حول الوضع الراهن، وتحديد

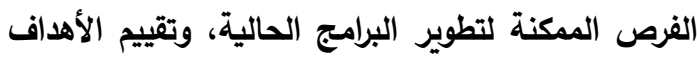

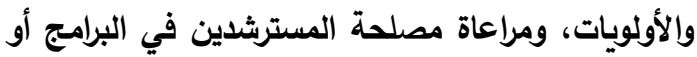
القرارات المتعلقة بهم، والتمكين من اتخاذ قرارات سليمة

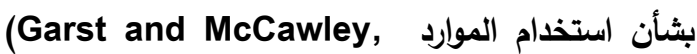
.2015: 28)

$$
\text { 2- الطرق الحديثة لتقدير الإحتياجات }
$$

نظرأ لتعدد طرق تقدير الإحتياجات، لذلك يفضل

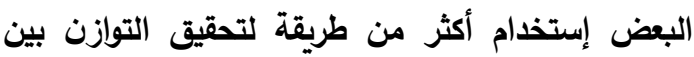
نقاط القوة والضعف بكل منها (Mulroy, 2008:2)،

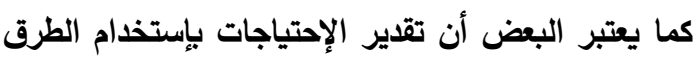

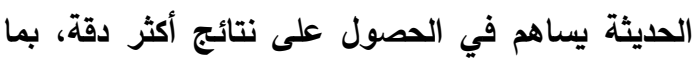
(Abdel- يمكن من تخطيط برامج إرشادية أكثر فعالية لنائل Maksoud and Gad-EI-Kareim, 2011:155) (Abdel-Maksoud, 2010)، والمدخل الجديد (Abdel-Maksoud and لتقدير الإحتياجات Saknidy, 2016) الإحتياجات الإششادية والتدريبية في مجال الإرشاد

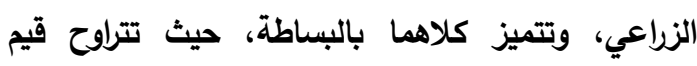
الاحتياج المحسوب فيهما ما بين (صفر - 1). وتعتمد

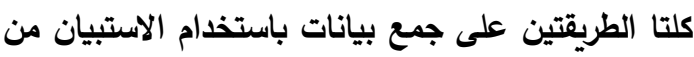

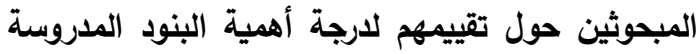

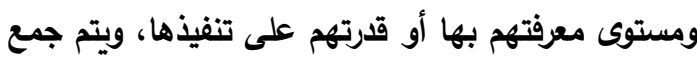
هذه البيانات باستخدام مقياس خماسي على على غرار مقياس ليكرت يتراوح من منخفضة جداً (1) إلى مرتفعة جداً (5)، ثم يتم جدولة البيانات المجمعة كتوزيعات ثنائية المتغير (للأهمية والمعرفة)، (للأهمية والقدرة على الثى التنفيذ) لكل بند من البنود المدروسة في صورة جدول
(Saknidy, 2016: 102) وتجدر الإثارة إلى أن عملية تحديد الإحتياجات هي عبارة عن تحديد الفجوة

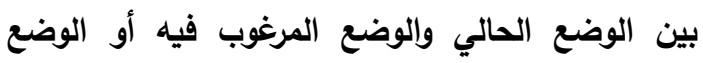
الأمثل، أما عملية تقدير الإحتياجات فهي العملية التي يتم من خلاهها تحديد الإحتياجات ثم ترتيبها حسب الإسب

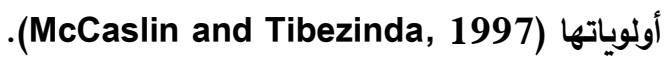
لقد تطور مفهوم تقدير الإحتياجات منذ منتصف

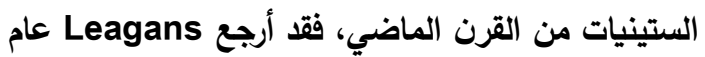

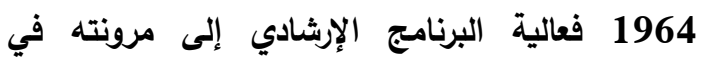

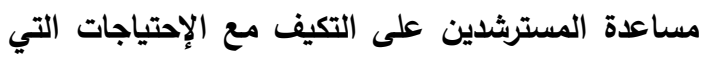
تفرضها البيئة المتغيرة، كما وضع تقدير الإحتياجات كأولى خطوات نموذجه لتخطيط البرامج الإرشادية. ويعتمد تقدير إحتياجات المسترشدين على سمتين أساسيتين: أولهما، أن الإحتياجات تعتمد على وجهة نظر المسترشد، فما قد يحدده شخص ما كإحتياج قد يكون غير ذئ الإني

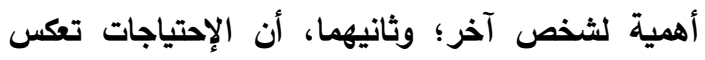

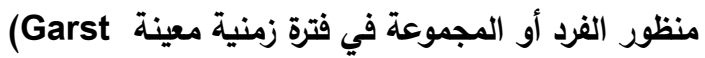
.and McCawley, 2015: 27)

إن تقدير الإحتياجات الإششادية عملية يقودها

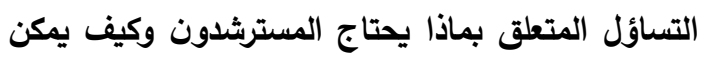
تلبية تلك الإحتياجات؟، ويمثل تقدير الإحتياجات مدخل

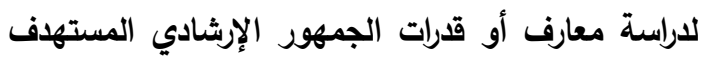
وتفضيلاته الإرشادية حول موضوع معين، حيث يتيح

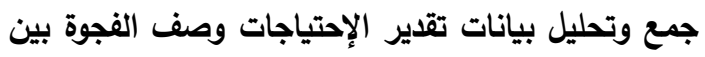

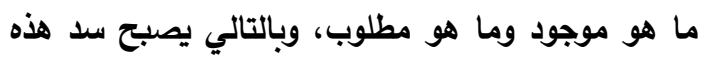

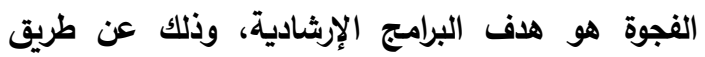
تحديد المحتوى الإششادي المناسب والمفيد والمقبول لهؤلاء المسترشدين .Donaldson and Franck, 2016: 5) ويمثل تقدير الإحتياجات الخطوة الأولى في تخطيط البرامج الإششادية، فبمجرد تحديد الإحتياجات والأولويات، يمكن استخدام الموارد بثكل أكثر كفاءة، ويمكن تزويد

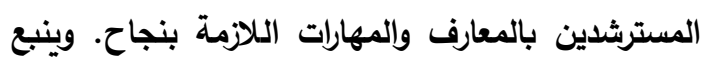
المنطق وراء تقدير الإحتياجات الإرشادية من الرغبة في 
Delta المعرفي أو التنفيذي من المعادلة التالية: قيمة

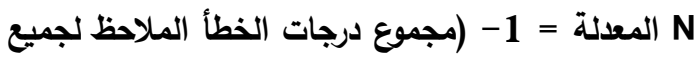
الخلايا التي بها تكرار). أما فيما يتعلق بالمدخل الجديد لتقدير الإحتياجات (Abdel-Maksoud and Saknidy, 2016) يعتمد بثكل مشابه على منطقية أن أعلى قيمة للحاجة

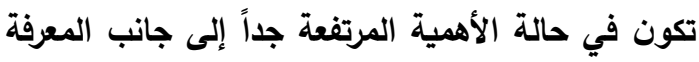

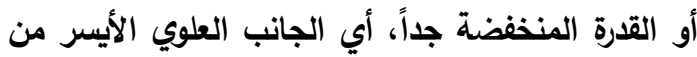

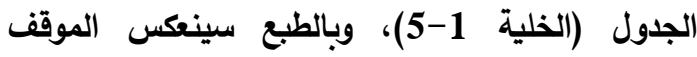
بالنسبة للخلية (5-1). ولكن المدخل الجديد لتقدير الإحتياجات يستند إلى أوزان الخلايا وليس الخطأ النسبي

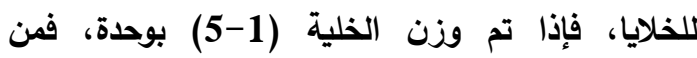
المفترض أن تكون الخلية (5-1) موزونة إلى الصفر.

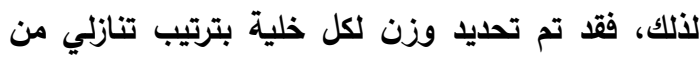

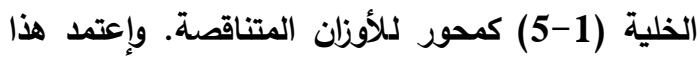
الدخل على حساب الارجة المرجحة لكل خلية بها تكرار عن طريق ضرب تكرار الخلية × وزن الخلية (أوزان الخلايا موضحة بجدول 2)، ثم حساب المؤشر الإجمالي

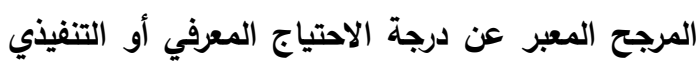

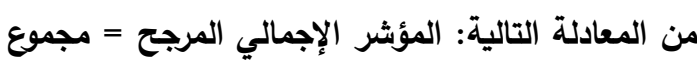
الدرجات المرجحة ؛ العدد الإجمالي للمبحوثين.
خماسي (5 × 5) تحتوي خلاياه على التوزيع التكراري للمبحوثين وفقاً لتقييمهم للبنود المدروسة خدئ. وفيما يتعلق بمعادلة Delta N المعدلة - Abdel

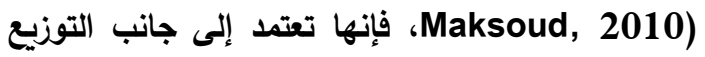
الملاحظ للمبحوثين في صورة الجدول خماسي التوزيع على قيم لوزن الخطأ النسبي لجميع خلايا الجدول (أوزان الخطأ موضحة بجدول 1)، حيث تستند إلى لفئ

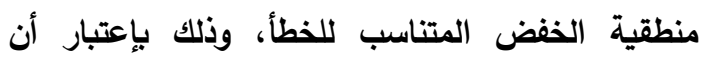

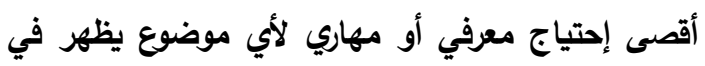

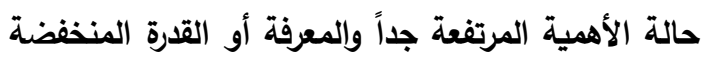

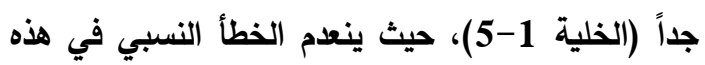

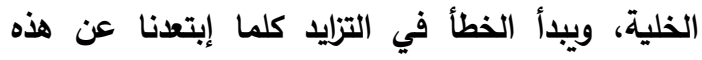
الخلية في أي اتجاه، ويصل قمته في حالة الخلية (51) حيث تصل قيمة الخطأ إلى الواحد الصحيح. وتم تطوير هذه المعادلة لتجنب عيوب معادلة Delta N التي قدمها Misanchuk عام 1984، والمتمثلة في أنها

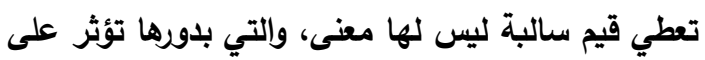

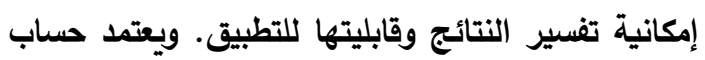

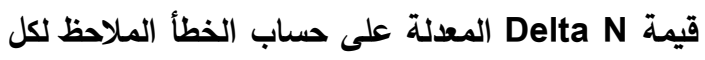
خلية بها تكرار عن طريق ضرب وزن الخطأ للخلية ×

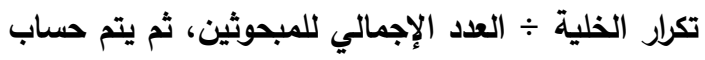
قيمة Delta N المعدلة المعبرة عن درجة الاحتياج

\begin{tabular}{|c|c|c|c|c|c|}
\hline \multicolumn{6}{|c|}{ دول (1): أوزان الخطأ المستخدمة لحساب قيمة Delta N المعدلة } \\
\hline \multicolumn{5}{|c|}{ 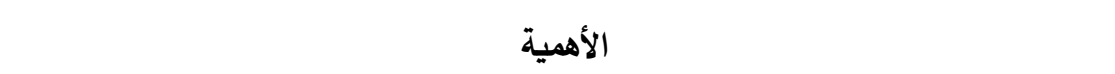 } & \multirow{2}{*}{ 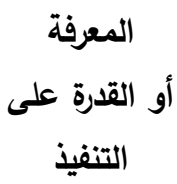 } \\
\hline 5 & 4 & 3 & 2 & 1 & \\
\hline 0,000 & 0,1768 & $\mathbf{0 , 3 5 3 6}$ & 0,5303 & 0,7071 & 1 \\
\hline 0,1768 & 0,2500 & 0,3953 & 0,5590 & 0,7289 & 2 \\
\hline $\mathbf{0 , 3 5 3 6}$ & 0,3953 & 0,5000 & 0,6374 & 0,7906 & 3 \\
\hline 0,5303 & 0,5590 & 0,6374 & 0,7500 & 0,8839 & 4 \\
\hline 0,7071 & 0,7289 & 0,7906 & 0,8839 & 1 & 5 \\
\hline
\end{tabular}


جدول (2): أوزان الخلايا وفقاً للمدخل الجديد لتقدير الإحتياجات

\begin{tabular}{|c|c|c|c|c|c|}
\hline \multicolumn{5}{|c|}{ الأهمية } & \multirow{2}{*}{ 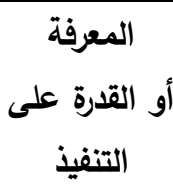 } \\
\hline 5 & 4 & 3 & 2 & 1 & \\
\hline 1,000 & 0,875 & 0,750 & 0,625 & 0,500 & 1 \\
\hline 0,875 & 0,750 & 0,625 & 0,500 & 0,375 & 2 \\
\hline 0,750 & 0,625 & 0,500 & 0,375 & 0,250 & 3 \\
\hline 0,625 & 0,500 & 0,375 & 0,250 & 0,125 & 4 \\
\hline 0,500 & 0,375 & 0,250 & 0,125 & 0,000 & 5 \\
\hline
\end{tabular}

المصدر: Abdel-Maksoud and Saknidy (2016: 104)

صفر - 0,33)، ومتوسط (متوسط حسابي يتراوح ما بين

0,34 - 0,66)، ومرتفع (متوسط حسابي يتراوح ما بين

.$(1-0,67$

وتم اختيار أكبر مركزين بمحافظة أسيوط من حيث

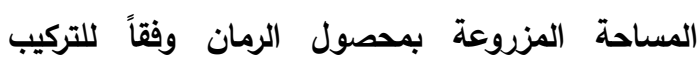
المحصولي للمحافظة لعام 2019، وهما مركزي البداري

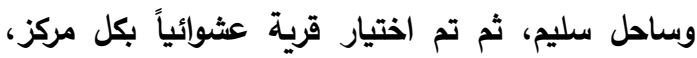
وأسفر ذلك عن اختيار قرية النواميس بمركز البداري فئي

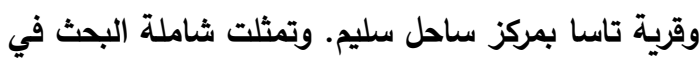
جميع زراع الرمان بالقريتين المختارتين (581 مزارعاً

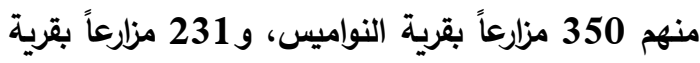
تاسا)، ولتحديد حجم العينة تم استخدام جدول تحديد

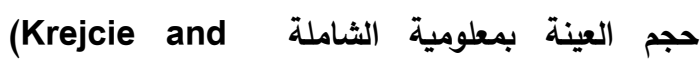
(Morgan, 1970: 608) وقد تبين من الجدول أن حجم العينة المناسب هو 234 مبحوثاً، وتم توزيعهر من الجئ

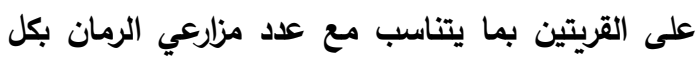
قرية (141 مزارعاً بقرية النواميس، و93 وقيع مزارعاً بقرية تاسا)، وقد تم اختيار أفراد العينة المبحوثين عثوائياً

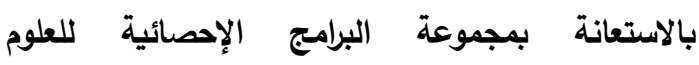

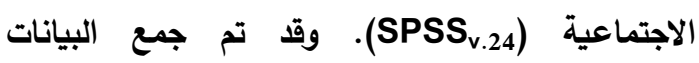
باستخدام إستمارة الاستبيان خلال شهري سبتمبر وأكتوبر 2019. وتم تحليل البيانات باستخدام كل من مجموعة
طربقة إجراء البحث تم حصر التوصيات الخاصة بمحصول الرمان استناداً إلى الأجندة الثهرية لخدمة محصول الرمان، والثواردة

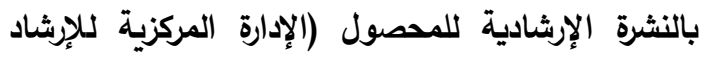
الزراعي، 2014)، إلى جانب الرجوع إلى بعض العضاء العضاء

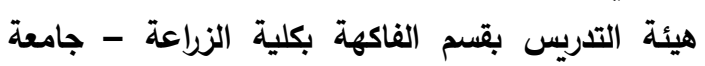
أسيوط، وقد أسفر ذلك عن قائمة نهائية مكونة من 30 توصية مقسمة لستة مجموعات حسب شهور السنة (شهرين لكل مجموعة). ولتقدير الإحتياجات الإرشادية المعرفية والتنفيذية للزراع المبحوثين، فقد تم استخدام (Abdel-Maksoud, المعدلة Delta N معادلة المبنة (Abdel- 2010، والمدخل الجديد لتقدير الإحتياجات (Abde) Maksoud and Saknidy, 2016) سلفاً في الإطار النظري، وذلك بعد قياس درجة الأهمية

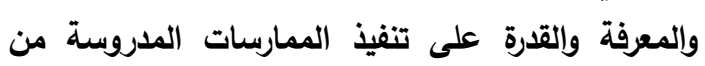

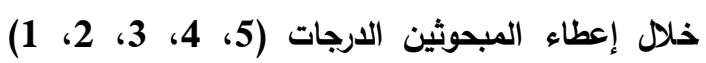
للاستجابات (مرتفعة جدا، مرتفعة، متوسطة، منخفضة، منخفضة جذا) على الترتيب لكل توصية من التوصيات المدروسة، وحيث إن المدى النظري لدرجات الإحتياجات

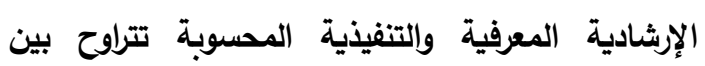
(صفر - 1)، فقد تم تقسيم الاحتياج المعرفي والتنفيذي إلى ثلاث فئات: منخفض (متوسط حسابي يتراوح ما بين 
لخصائصهم المبينة، ومنه يلاحظ أن النسبة الغالبة من المبحوثين كانت أعمارهم في الفئة من 50 سنة فأكثر (49,6\%)، وتراوحت حيازتهم المزرعية سواء الإجمالية

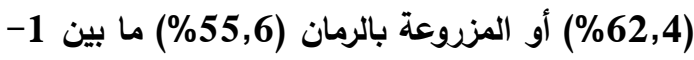

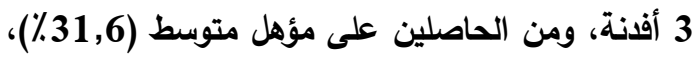
ولم يسبق لهم السفر للخارج (87,6\%).
البرامج الإحصائية للعلوم الاجتماعية (SPSS.24)،

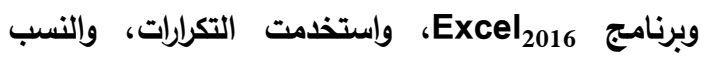
المئوية، والمتوسط الحسابي لعرض النتائج. النتائج أولاً: خصائص الزراع المبحوثين:

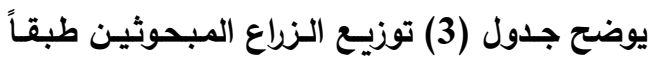

جدول (3): توزيع الزراع المبحوثين طبقاً لخصائصهم المبينة (ن= 234)

\begin{tabular}{|c|c|c|c|}
\hline$\%$ & العدد & الخصائص & م \\
\hline \multicolumn{3}{|r|}{ السن: ال } & 1 \\
\hline 19,2 & 45 & أقل من 40 سنة & \\
\hline 31,2 & 73 & -40 & \\
\hline 49,6 & 116 & 50 سنة فأكثر & \\
\hline \multicolumn{3}{|r|}{ مساحة الحيازة المزرعية: } & 2 \\
\hline 9,4 & 22 & أقل من فدان & \\
\hline 62,4 & 146 & 3-1 أفدنة & \\
\hline 28,2 & 66 & 4 أفدنة فاكثر & \\
\hline \multicolumn{3}{|r|}{ المساحة المزروعة بالرمان: } & 3 \\
\hline 23,1 & 54 & أقل من فدان & \\
\hline 55,6 & 130 & 3-1 أفدنة & \\
\hline 21,3 & 50 & 4 أفذنة فاكثر & \\
\hline \multicolumn{3}{|r|}{ الحالة التعليمية: } & 4 \\
\hline 9,8 & 23 & أمي & \\
\hline 10,7 & 25 & يقرأ ويكتب & \\
\hline 4,3 & 10 & إبتدائي & \\
\hline 19,7 & 46 & إعدادي & \\
\hline 31,6 & 74 & ثانوي & \\
\hline 23,9 & 56 & جامعي & \\
\hline \multicolumn{3}{|r|}{ عدد سنوات السفر للخارج: } & 5 \\
\hline 87,6 & 205 & لم يسافر مطلقاً & \\
\hline 7,3 & 17 & أقل من 5 سنوات & \\
\hline 5,1 & 12 & 5 سنوات فأكثر & \\
\hline
\end{tabular}


موضع الاراسة قد بلغت 0,582، 0,661 على الترتيب،

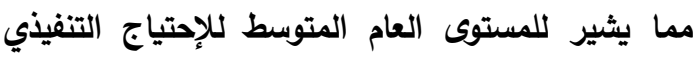

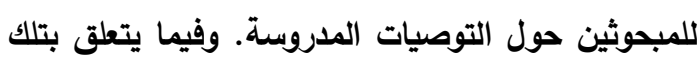
التوصيات كل على حده، يتبين وقوع 11 توصية (\%36,7) داخل فئة الإحتياج التنفيذي المرتفع للزباع

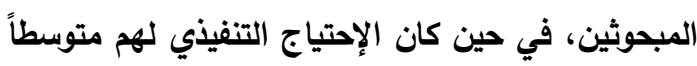

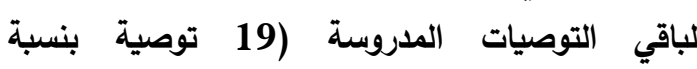
. $(\% 63,3$

ويتبين من النتائج السابقة تثابه المستوى العام

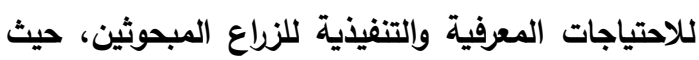
وقع كلاهما داخل المستوى المتوسط، كما يتضح توافق لتوني

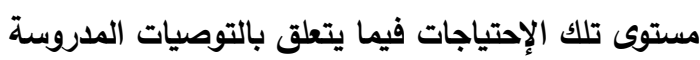
كل على حده، فيما عدا توصية وحيدة (التقليم الثتوي

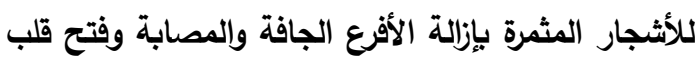

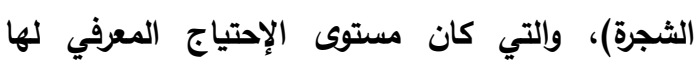

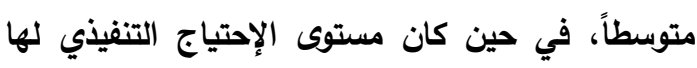
مرتفعاً.
ثانياً: تحديد الإحتياجات المعرفية والتنفيذية للزراع المبحوثين المتعلقة بالتوصيات الخاصة

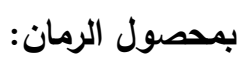

تثير النتائج الواردة بجدول (4) إلى أن المتوسط

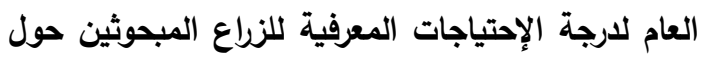
التوصيات الخاصة بمحصول الرمان باستخدام طريقتي Delta N بلغ 0,548، 0,622 على الترتيب، مما يثير للمستوى المتوسط للإحتياج المعرفي للمبحوثين بوجه عام حول

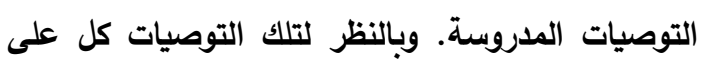
حده، يتبين وقوع 10 توصيات (33,3\%) داخل فئة الإحتياج المعرفي المرتفع للزراع المبحوثين، في حين كان الإحتياج المعرفي لهم متوسطاً لباقي التوصيات المدروسة (20 توصية بنسبة 66,7\%).

وتوضح النتائج الواردة بنفس الجدول أن المتوسط

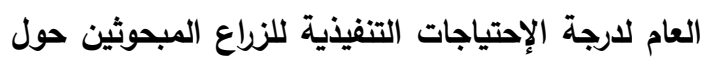
التوصيات الخاصة بمحصول الرمان باستخدام الطريقتين

جدول (4): متوسطات درجات الإحتياجات المعرفية والتنفيذية للزراع المبحوثين حول التوصيات الخاصة بمحصول الرمان:

\begin{tabular}{|c|c|c|c|c|c|}
\hline \multicolumn{2}{|c|}{ الإحتياج التنفيذي } & \multicolumn{2}{|c|}{ الإحتياج المعرفي } & \multirow{3}{*}{ 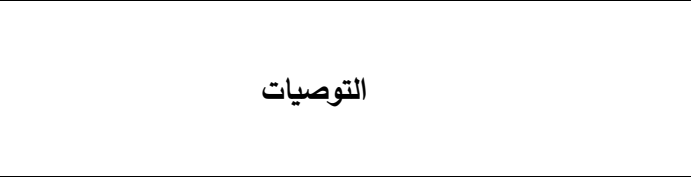 } & \multirow{3}{*}{ s } \\
\hline 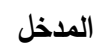 & Delta $N$ & 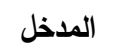 & Delta $N$ & & \\
\hline الجديد & المعدلة & الجديد & المعلة & & \\
\hline \multicolumn{6}{|c|}{ يناير وفبراير: } \\
\hline 0,760 & 0,702 & 0,733 & 0,669 & رش الأثجار بعد التقليم بزيت معدني واوكسي كلورو النحاس & 1 \\
\hline 0,584 & 0,499 & 0,559 & 0,471 & إضافة السماد البلدي أو سماد الكمبوست مع السوبر فوسفات & 2 \\
\hline 0,552 & 0,448 & 0,524 & 0,440 & ري الأشجار رية غزيرة للمساعدة على التزهير & 3 \\
\hline 0,632 & 0,550 & 0,605 & 0,527 & المتوسط & \\
\hline \multicolumn{6}{|c|}{ مارس وأبريل: } \\
\hline 0,571 & 0,453 & 0,526 & 0,443 & زراعة الثتلات (عمر سنة) في الأرض المستديمة & 4 \\
\hline 0,812 & 0,703 & 0,728 & 0,684 & مقاومة حفار السلق والأكاروس بالمبيدات الموصى بها & 5 \\
\hline 0,591 & 0,558 & 0,582 & 0,447 & إضافة الدفعة الأولي من سلفات النشادر وسلفات البوتاسيوم & 6 \\
\hline 0,790 & 0,711 & 0,768 & 0,695 & رش الأشجار بمحلول السماد الورقي & 7 \\
\hline 0,691 & 0,606 & 0,651 & 0,567 & المتوسط & \\
\hline
\end{tabular}


تابع جدول (4): متوسطات درجات الإحتياجات المعرفية والتنفيذية للزراع المبحوثين حول التوصيات الخاصة بمحصول الرمان:

\begin{tabular}{|c|c|c|c|c|c|}
\hline \multicolumn{2}{|c|}{ الإحتياج التنفيذي } & \multicolumn{2}{|c|}{ الإحتياج المعرفي } & \multirow[b]{2}{*}{ التوصيات } & \multirow[b]{2}{*}{ م } \\
\hline الجدخل & $\begin{array}{c}\text { Delta N } \\
\text { المعدلة }\end{array}$ & الجدخل & $\begin{array}{c}\text { Delta N } \\
\text { المعدلة }\end{array}$ & & \\
\hline \multicolumn{6}{|c|}{ 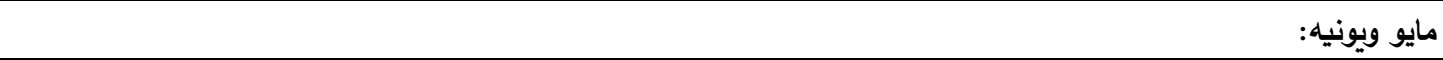 } \\
\hline 0,566 & 0,471 & 0,544 & 0,460 & إضافة الدفعة الثانية من سلفات النشادر وسلفات البوتاسيوم & 8 \\
\hline 0,592 & 0,467 & 0,565 & 0,454 & إجراء العزيق الصيفي الخفيف & 9 \\
\hline 0,652 & 0,608 & 0,629 & 0,587 & التقليم الصيفي وإزالة السرطانات والأفرخ المائية & 10 \\
\hline 0,571 & 0,469 & 0,554 & 0,431 & خف الثمار مع ترك ثمرة واحدة أو اثنين في العنقود & 11 \\
\hline 0,870 & 0,723 & 0,772 & 0,678 & طلاء جذوع الأثجار بمحلول الجير وكبريتات النحاس لحمايتها من حفار الساق & 12 \\
\hline 0,650 & 0,548 & 0,613 & 0,522 & المتوسط & \\
\hline \multicolumn{6}{|c|}{ يوليو وأغسطس: } \\
\hline 0,715 & 0,680 & 0,697 & 0,666 & مقاومة دودة ثمار الرمان بالمبيدات الموصى بها & 13 \\
\hline 0,628 & 0,543 & 0,595 & 0,480 & الري على فترات متقاربة حتى اكتمال نمو الثمار & 14 \\
\hline 0,631 & 0,589 & 0,580 & 0,537 & إضافة الدفعة الأخيرة من سلفات النشادر وسلفات البوتاسيوم & 15 \\
\hline 0,744 & 0,685 & 0,708 & 0,676 & الرش بكلوريد الكالسيوم أو سلفات الزنك لتقليل تثقق الثمار & 16 \\
\hline 0,759 & 0,706 & 0,691 & 0,680 & الرش بماء الجير لتقليل التنحيس (لفحة الثمس) & 17 \\
\hline 0,695 & 0,641 & 0,654 & 0,608 & المتوسط & \\
\hline \multicolumn{6}{|c|}{ سبتمبر وأكتوبر: } \\
\hline 0,611 & 0,583 & 0,584 & 0,490 & وقف الري قبل الجمع بفترة كافية & 18 \\
\hline 0,633 & 0,581 & 0,559 & 0,483 & جمع المحصول باستخدام مقص الجمع & 19 \\
\hline 0,848 & 0,754 & 0,779 & 0,719 & غمر الثمار في محلول سلفات الكالسيوم لتقليل أعفان الثمار & 20 \\
\hline 0,571 & 0,482 & 0,543 & 0,449 & وضع الثمار بعد الجمع على فرشة من البولي إيثلين & 21 \\
\hline 0,755 & 0,680 & 0,729 & 0,677 & جمع المحصول بعد مرور 3 أسابيع من الرش بالمبيدات & 22 \\
\hline 0,556 & 0,448 & 0,542 & 0,443 & عزيق الأرض بعد جمع المحصول & 23 \\
\hline 0,583 & 0,490 & 0,513 & 0,470 & ري الأرض ريـة غزيرة بعد جمع المحصول & 24 \\
\hline 0,651 & 0,574 & 0,607 & 0,533 & المتوسط & \\
\hline \multicolumn{6}{|c|}{ 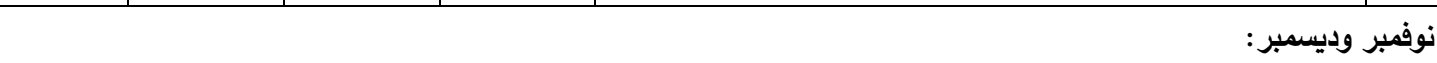 } \\
\hline 0,539 & 0,474 & 0,512 & 0,453 & إجراء العزيق الثتوي & 25 \\
\hline 0,595 & 0,517 & 0,558 & 0,488 & مقاومة الحشرات القشرية والبق الدقيقي بالمبيدات الموصى بها & 26 \\
\hline 0,841 & 0,698 & 0,785 & 0,665 & تقليم الثتلات الحديثة (عر 2-3 سنوات) لتربيتها بإرتفاع 60-80 سم & 27 \\
\hline 0,691 & 0,669 & 0,654 & 0,613 & قالتقليم الشتوي للأشجار المثمرة بإزالة الأفرع الجافة والمصابة وفتح & 28 \\
\hline 0,647 & 0,576 & 0,562 & 0,525 & تجهيز العقل الناتجة من تقليم الثتاء وزراعتها في المشتل & 29 \\
\hline 0,567 & 0,494 & 0,537 & 0,428 & تقليم الأشجار المسنة والتي لا تعطي محصول لتجديد الأفرع & 30 \\
\hline 0,647 & 0,571 & 0,601 & 0,529 & المتوسط & \\
\hline 0,661 & 0,582 & 0,622 & 0,548 & مبط العام & 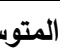 \\
\hline
\end{tabular}


وفقاً للاحتياجات المعرفية والتنفيذية للزراع

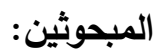

توضح النتائج الواردة بجدول (5) ترتيب التوصيات

الخاصة بمحصول الرمان وفقاً للاحتياجات المعرفية

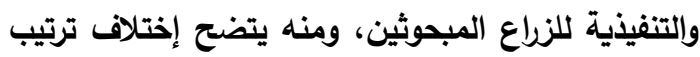

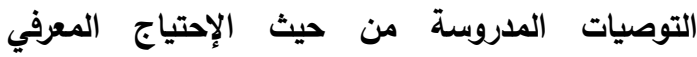

والتنفيذي للزراع المبحوثين وفقاً للطريقتين المستخدمتين

في الدراسة، وبالتالي فحتى يمكن ترتيب أولويات بنود الماتئين

تلك الإحتياجات، فقد تم جمع رتب كل توصية من

التوصيات المدروسة بكلا الطريقتين، ثم ترتيب التوصيات

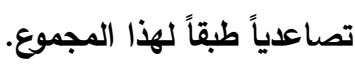

وبالنظر للمتوسط العام لمجموعات التوصيات حسب

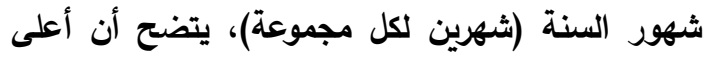
متوسط للإحتياج المعرفي والتنفيذي للزراع المبحوثين بكلتا الطريقتين المستخدمتين في الدراسة كان لتوصيات الفترة الرابعة (يوليو وأغسطس)، وهي الفترة التي تسبق ليقي جمع المحصول مباشرة، وتحتوي على توصيات متنوعة تتعلق بالري والتسميد ومقاومة الأمراض والآفات، بينما كان أقل متوسط للإحتياج المعرفي والتنفيذي للمبحوثين من نصيب الفترة الأولى (يناير وفبراير). ثالثاً: ترتيب التوصيات الخاصة بمحصول الرمان

جدول (5): ترتيب التوصيات الخاصة بمحصول الرمان وفقاً للاحتياجات المعرفية والتنفيذية للزراع المبحوثين

\begin{tabular}{|c|c|c|c|c|c|c|c|}
\hline \multicolumn{3}{|c|}{ الترتيب وفقاً للاحتياج التنفيذي } & \multicolumn{3}{|c|}{ الترتيب وفقاً للاحتياج المعرفي } & \multirow[b]{2}{*}{ التوصيات } & \multirow[b]{2}{*}{ b } \\
\hline 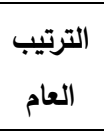 & 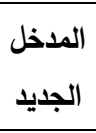 & $\begin{array}{l}\text { Delta } \\
\text { N } \\
\end{array}$ & التعام & الجلديد & $\begin{array}{l}\text { Delta } \\
\text { N } \\
\text { المعدلة }\end{array}$ & & \\
\hline \multicolumn{8}{|c|}{ يناير وفبراير: } \\
\hline 7 & 6 & 6 & 7 & 5 & 8 & كلورو النحاس بأثجار بعد التقليم بزيت معدني واوكسي & 1 \\
\hline 20 & 21 & 20 & 19 & 19,5 & 19 & إلسوبرة السماد البلاي أو سماد الكمبوست مع & 2 \\
\hline 30 & 29 & 29,5 & 29,5 & 28 & 28 & ري الأثجار رية غزيرة للمساعدة على التزهير & 3 \\
\hline \multicolumn{8}{|c|}{ مارس وأبريل: } \\
\hline 26,5 & 24 & 28 & 28 & 27 & 26,5 & زراعة الشتلات (عمر سنة) في الأرض المستديمة & 4 \\
\hline 4 & 4 & 5 & 4 & 7 & 3 & مقاومة حفار السلق والأكاروس بالمبيدات الموصىبها & 5 \\
\hline 18,5 & 20 & 17 & 21 & 15 & 25 & وإضلفافة الدفعة الأولي من سلفات النشادر & 6 \\
\hline 3 & 5 & 3 & 2 & 4 & 2 & رش الأثجار بمحلول السماد الورقي & 7 \\
\hline \multicolumn{8}{|c|}{ مايو ويونيه: } \\
\hline 26,5 & 27 & 25 & 22 & 23 & 21 & وإضلفاتة الافعة الثانية من سلفات النشادر & 8 \\
\hline 22 & 19 & 27 & 20 & 17 & 22 & إجراء العزيق الصيفي الخفيف & 9 \\
\hline 12 & 12 & 12 & 12 & 12 & 12 & التقليم الصيفي وإزالة السرطانات والأفرخ المائية & 10 \\
\hline 25 & 24 & 26 & 25 & 22 & 29 & خف الثمار مع ترك ثمرة واحدة أو اثثين في العنقود & 11 \\
\hline 1,5 & 1 & 2 & 3 & 3 & 5 & طلاء جذوع الأثجار بمحلول الجير وكبريتات & 12 \\
\hline
\end{tabular}


تابع جدول (5): ترتيب التوصيات الخاصة بمحصول الرمان وفقاً للاحتياجات المعرفية والتنفيذية للزراع المبحوثين

\begin{tabular}{|c|c|c|c|c|c|c|c|}
\hline \multicolumn{3}{|c|}{ الترتيب وفقاً للاحتياج التنفيذي } & \multicolumn{3}{|c|}{ الترتيب وفقاً للاحتياج المعرفي } & \multirow[b]{2}{*}{ 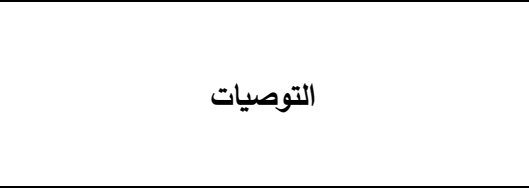 } & \multirow[b]{2}{*}{ r } \\
\hline 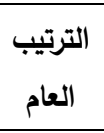 & 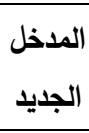 & $\begin{array}{l}\text { Delta } \\
\text { N } \\
\end{array}$ & الت الترتيب & 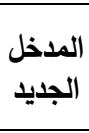 & $\begin{array}{l}\text { Delta } \\
\text { N } \\
\text { المعدلة }\end{array}$ & & \\
\hline \multicolumn{8}{|c|}{ بوليو وأغسطس: } \\
\hline 10 & 10 & 9,5 & 10 & 9 & 9 & مقاومة دودة ثمار الرمان بالمبيدات الموصى بها & 13 \\
\hline 17 & 16 & 18 & 15 & 13 & 18 & الري على فترات متقاربة حتى اكتمال نمو الثمار & 14 \\
\hline 13 & 15 & 13 & 13,5 & 16 & 13 & وإضلفاتة الدفعة الأخيرة من سلفات النثادر & 15 \\
\hline 8 & 9 & 8 & 9 & 8 & 7 & التقليل تثثقى الثمار الكالسيوم أو سلفات الزنك & 16 \\
\hline 6 & 7 & 4 & 8 & 10 & 4 & الرش بماء الجير لتقليل التحيس (لفحة الثمس) & 17 \\
\hline \multicolumn{8}{|c|}{ سبتمبر وأكتوبر: } \\
\hline 16 & 17 & 14 & 13,5 & 14 & 15 & وقف الري قبل الجمع بفترة كافية & 18 \\
\hline 14,5 & 14 & 15 & 17 & 19,5 & 17 & جمع المحصول باستخذام مقص الجمع & 19 \\
\hline 1,5 & 2 & 1 & 1 & 2 & 1 & غتقليل أعفان الثمار فحلول سلفات الكالسيوم & 20 \\
\hline 23,5 & 24 & 23 & 23 & 24 & 24 & إيثلين الثمار بعد الجمع على فرشة من البولي & 21 \\
\hline 9 & 8 & 9,5 & 6 & 6 & 6 & بالمبيدات المحصول بعد مرور 3 أسابيع من الرش & 22 \\
\hline 29 & 28 & 29,5 & 26 & 25 & 26,5 & عزيق الأرض بعد جمع المحصول & 23 \\
\hline 21 & 22 & 22 & 24 & 29 & 20 & ري الأرض رية غزيرة بعد جمع المحصول & 24 \\
\hline \multicolumn{8}{|c|}{ نوفمبر وديسمبر : } \\
\hline 28 & 30 & 24 & 27 & 30 & 23 & إجراء العزيق الشتوي & 25 \\
\hline 18,5 & 18 & 19 & 18 & 21 & 16 & مقالمبيدات الموصى بهات القشرية والبق الدقيقي & 26 \\
\hline 5 & 3 & 7 & 5 & 1 & 10 & 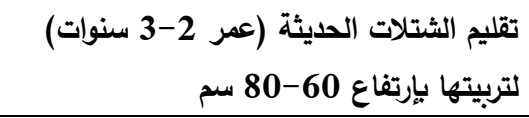 & 27 \\
\hline 11 & 11 & 11 & 11 & 11 & 11 & 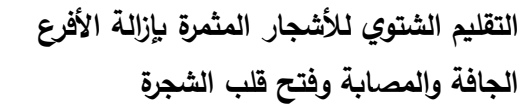 & 28 \\
\hline 14,5 & 13 & 16 & 16 & 18 & 14 & تجزيز العقل الناتجة من تقليم الثتاء & 29 \\
\hline 23,5 & 26 & 21 & 29,5 & 26 & 30 & تتجليم الأثجار المسنة والتي لا تعطي محصول & 30 \\
\hline
\end{tabular}




\section{المراجع}

الإدارة العامة للثقافة الزراعية (2015). الرمان، نثرة

$$
\text { فنية رقم (4)، القاهرة. }
$$

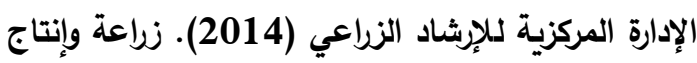

$$
\text { الرمان، نشرة إرشادية رقم (1324)، القاهرة. }
$$

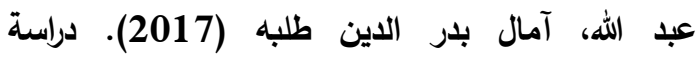

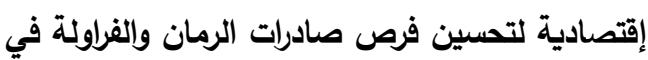

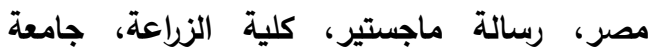

$$
\text { أسيوط. }
$$

وزارة الزراعة واستصلاح الأراضي (2018). نشرة

الإحصاءات الزراعية، الجزء الثاني، المحاصيل

$$
\text { الصيفية وإلنيلية، القاهرة. }
$$

وزارة الزراعة واستصلاح الأراضي (2019). نشرة

الإحصاءات الزراعية، الجزء الثاني، المحاصيل

الصيفية وإلنيلية، القاهرة.

Abdel-Maksoud, B. (2010). Developing a modified delta $\mathbf{N}$ method for training needs assessment, Journal of Agricultural Extension and Rural Development, 2(10): 205-210. Available at:

https://academicjournals.org/journal/J

AERD/article-full-textpdf/E3DFD7A10358

Abdel-Maksoud, B. and Gad-El-Kareim, E. (2011). Farmers' perception of sugar cane production and marketing problems in Qena and Aswan Governorates, Egypt, Nature and Science, 9(5): 155-162. Available at: http://www.sciencepub.net/nature/ns0 905/

Abdel-Maksoud, B. and Saknidy, S. (2016). A new approach for training needs assessment, Journal of Human Resource and Sustainability Studies, 4 (2): 102-109. Available at: https://www.scirp.org/pdf/JHRSS 201 6061714354590.pdf

Altschuld, J. and Watkins, R. (2014). A primer on needs assessment: More than 40 years of research and
ويثير الترتيب النهائي للتوصيات المدروسة وفقاً

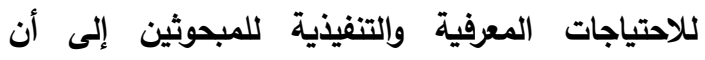
توصيات غمر الثمار في محلول سلفات الكالسيوم لتقليل أعفان الثمار، ورش الأثجار بمحلول السماد الورقي، ولئل

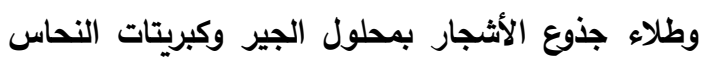
لحمايتها من حفار الساق، ومقاومة حفار الساق الاقدار لونير والأكاروس بالمبيدات الموصى، وتقليم الثتلات الحديثة

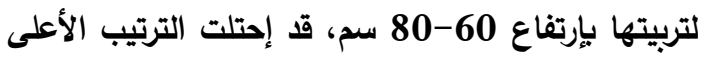

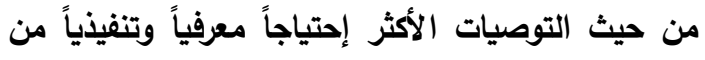
جانب الزياع المبحوثين. كما يلاحظ اختلاف أولويات الإئي الإحتياجات المعرفية والتنفيذية حول أغلب التوصيات المدروسة (23 توصية بنسبة 76,6\%)، في حين 7) يلاحظ التطابق التام في ترتيب باقي التوصيات توصيات بنسبة 23,3\%) ما بين الإحتياجات المعرفية والتنفيذية للزراع المبحوثين.

$$
\text { التوصيات }
$$

في ضوء النتائج التي توصلت إليها الدراسة، يمكن التوصية بالعمل على إعداد برنامج إرشادي لزيادة معارف

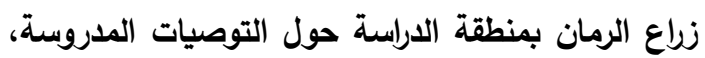

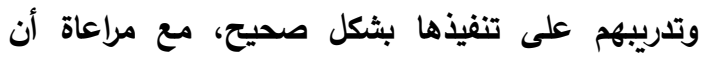

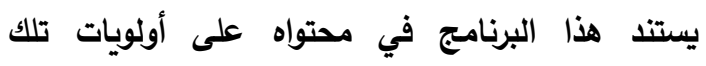
التوصيات، سواء من حيث توصيات الفترة التي إثتملت على المتوسط الأعلى للاحتياج المعرفي والتنفيذي للزراع

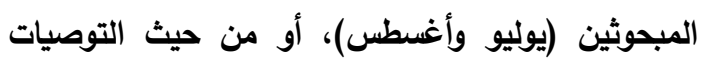

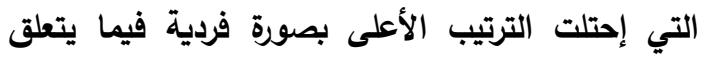
بالاحتياج المعرفي والتنفيذي للزراع المبحوثين وهي: غمر الثمار في محلول سلفات الكالسيوم لتقليل أعفان الثمار، ورش الأثجار بمحلول السماد الورقي، وطلاء جذوع الأثجار بمحلول الجير وكبريتات النحاس لحمايتها

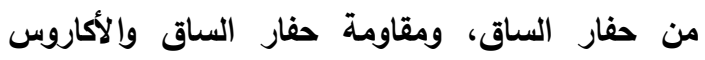
بالمبيدات الموصي، وتقليم الثتلات الحديثة لتربيتها بارتفاع 60-80 سم. 
Krejcie, R. and Morgan, D. (1970). Determining sample size for research activities, Educational and Psychological Measurement, 30: 607610. Available at: https://journals.sagepub.com/doi/pdf/1 $0.1177 / 001316447003000308$

McCaslin, N. and Tibezinda, J. (1997). Assessing target group needs. In: Swanson, B., Bentz, R. and Sofranko, A. (Eds.). Improving agricultural extension: A reference manual, FAO, Rome. Available at: http://www.fao.org/3/w5830e/w5830e07 htm

McCawley, P. (2009). Methods for conducting an educational needs assessment: Guidelines for cooperative extension system professionals, BUL 870 , College of Agricultural and Life Sciences, University of Idaho. Available at: https://www.extension.uidaho.edu/pub lishing/pdf/BUL/BUL0870.pdf

Mulroy, E. (2013). Community needs assessment, The Encyclopedia of Social Work, Oxford University Press, USA. Available at: https://oxfordre.com/socialwork/view/ 10.1093/acrefore/9780199975839.001.0 001/acrefore-9780199975839-e73?print $=$ pdf

Rogers, E. (2003). Diffusion of innovations, 5th Edition, The Free Press, New York.

Sofranko, A. and Khan, A. (1988). It's not that simple, Journal of Extension, 26 (4). Available at: https://www.joe.org/joe/1988winter/a3. php practice. In: Altschuld, J. and Watkins, R. (Eds.). Needs assessment: Trends and a view toward the future, New Directions for Evaluation, Wiley Periodicals, New Jersey. Available at: https://onlinelibrary.wiley.com/doi/epd f/10.1002/ev.20099

Donaldson, J. and Franck, K. (2016). Needs assessment guidebook for extension professionals, PB 1839, Institute of Agriculture, University of Tennessee. Available at: https://extension.tennessee.edu/publi cations/Documents/PB1839.pdf

Garst, B. and McCawley, P. (2015). Solving problems, ensuring relevance, and facilitating change: The evolution of needs assessment within cooperative extension, Journal of Human Sciences and Extension, 3 (2): 26-47. Available at: https://www.jhseonline.com/article/vie w/684/588

Goli, I., Langerodi, M. and Shahbazi, I. (2013). Modeling the educational needs of the rice cultivating women in Sari, International Journal of Agriculture and Crop Sciences, 6(10): 583-592. Available at: https://www.cabdirect.org/cabdirect/a bstract/20133372476

Goodwin, J. and Gouldthorpe, J. (2013). Small farmers, big challenges: A needs assessment of Florida smallscale farmers' production challenges and training needs, Journal of Rural Social Sciences, 28(1): 54-79. Available at: http://journalofruralsocialsciences.org /pages/Articles/JRSS\%202013\%2028/1 /JRSS\%202013\%2028\%201\%205479.pdf 


\title{
ASSESSMENT OF POMEGRANATE FARMERS' EXTENSION NEEDS IN SOME VILLAGES IN ASSIUT GOVERNORATE
}

\author{
M. M. M. Abdel-Ghany \\ Department of Rural Sociology \& Agricultural Extension, Faculty of Agriculture, Assiut \\ University, Assiut, Egypt, E-mail: abdelghany18@aun.edu.eg
}

\begin{abstract}
This research aimed at: (1) Identifying the knowledge and implementation needs for pomegranate farmers in some villages in Assiut governorate; (2) Arranging the pomegranate's recommendations according to the respondents' knowledge and implementation needs. The most recent methods were used for needs assessment (the modified Delta $N$ equation, and the new approach for assessing needs). The study was conducted on a random sample of 234 pomegranate farmers in two villages in Assiut Governorate. Data were collected by questionnaire during the period from September to October 2019. Frequencies, percentages and arithmetic mean were used for data presentation. The results indicated the overall medium level of the respondents' knowledge and implementation needs about the studied recommendations, as it became clear that about a third of the studied recommendations fall within the high knowledge and implementation needs for the respondents, while the knowledge and implementation needs was medium for the rest of the studied recommendations. It also came to clear that the highest knowledge and implementation needs' average was for the recommendations of the fourth period (July and August), which preceding the crop harvest. The results presented an arrangement of the studied recommendations according to the respondents' knowledge and implementation needs, and the study recommended preparing an extension program to increase the knowledge of pomegranate farmers in Assiut Governorate about the studied recommendations, and train them to implement these recommendations correctly, with the necessity that this program content should depend on the priorities of these recommendations, which the current study has reached to.
\end{abstract}

Key words: Extension Needs, Modified Delta N Equation, New Approach for Needs Assessment, Assiut Governorate

$$
\begin{aligned}
& \text { السادة المحكمين } \\
& \text { أ.د/ مصطفى عبدالحميد أبوالعينين كلية الزراعة - جامعة الأزهر - أسيوط }
\end{aligned}
$$

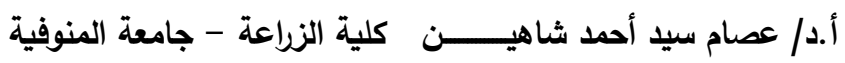

